\title{
Isometric hand grip strength measured by the Nintendo Wii Balance Board - a reliable new method
}

\author{
A. W. Blomkvist ${ }^{1}$, S. Andersen ${ }^{1,2}$, E. D. de Bruin ${ }^{3^{*}}$ and M. G. Jorgensen ${ }^{1}$
}

\begin{abstract}
Background: Low hand grip strength is a strong predictor for both long-term and short-term disability and mortality. The Nintendo Wii Balance Board (WBB) is an inexpensive, portable, wide-spread instrument with the potential for multiple purposes in assessing clinically relevant measures including muscle strength. The purpose of the study was to explore intrarater reliability and concurrent validity of the WBB by comparing it to the Jamar hand dynamometer.
\end{abstract}

Method: Intra-rater test-retest cohort design with randomized validity testing on the first session. Using custom WBB software, thirty old adults (69.0 \pm 4.2 years of age) were studied for reproducibility and concurrent validity compared to the Jamar hand dynamometer. Reproducibility was tested for dominant and non-dominant hands during the same time-of-day, one week apart. Intraclass correlation coefficient (ICC) and standard error of measurement (SEM) and limits of agreement (LOA) were calculated to describe relative and absolute reproducibility respectively. To describe concurrent validity, Pearson's product-moment correlation and ICC was calculated.

Results: Reproducibility was high with ICC values of $>0.948$ across all measures. Both SEM and LOA were low $(0.2-0.5 \mathrm{~kg}$ and $2.7-4.2 \mathrm{~kg}$, respectively) in both the dominant and non-dominant hand. For validity, Pearson correlations were high (0.80-0.88) and ICC values were fair to good (0.763-0.803).

Conclusion: Reproducibility for WBB was high for relative measures and acceptable for absolute measures. In addition, concurrent validity between the Jamar hand dynamometer and the WBB was acceptable. Thus, the WBB may be a valid instrument to assess hand grip strength in older adults.

Keywords: Nintendo Wii Balance Board, Isometric hand grip strength, Reliability, Reproducibility, Test-retest, Validity, Jamar hand dynamometer

\section{Background}

Muscle function is pivotal to overall physical fitness and a change in muscle strength is an important risk factor for functional decline, independent of disease processes [1]. Hence, the assessment of muscle function is an important measure in many situations. It may be assessed by proxies such as muscle mass or muscle strength. Compared to muscle mass, it is easier and more reliable to measure muscle function in terms of strength, particularly hand grip strength (HGS) [2, 3]. Accordingly,

\footnotetext{
*Correspondence: eling.debruin@hest.ethz.ch

${ }^{3}$ Department of Health Sciences and Technology, Institute of Human

Movement Sciences and Sport, ETH Zurich, Zurich, Switzerland

Full list of author information is available at the end of the article
}

HGS is a strong predictor of future disability [4] and mortality $[2,3,5-7]$ in the old and middle-aged $[4,7,8]$. In addition to being a marker for nutritional status $[9,10]$, low HGS is also associated with increased risk of postoperative complications, extended hospitalisation, higher re-submission rates and increased short-term mortality following acute admission [9-11].

In clinical settings, there are several methods for assessing muscle strength. Manual muscle testing (using a subjective scale from 0 to 5 ) is one of the most commonly used methods because of its simplicity and speed, however, a serious drawback is its crudeness [12, 13]. Another way of evaluating HGS is by using an objective handgrip dynamometer, which can be hydraulic, pneumatic, 
mechanical or electrical. The handgrip dynamometer has shown high reliability and validity when appropriately calibrated [14-16] and it can be useful for identifying individuals at high risk of poor disease outcomes [17]. The gold standard by which other dynamometers are evaluated is the Jamar hand dynamometer (JD) [16].

Most handgrip dynamometers are primarily found in the hands of health care professionals as they only measure HGS and prices range from 250 to 1484 USD. In contrast, the Nintendo Wii Balance Board (WBB) is widely available globally and it sells at approximately 60 USD. Moreover, the WBB has been demonstrated to be a reliable and valid instrument for the assessment of other physical characteristics such as balance [18] and reaction-time [19]. In 2014, an American research group demonstrated that both new and used WBB recorded static forces accurately in a laboratory setting [20]. Inspired by these findings, researchers at Aalborg University Hospital have developed software that enabled isometric strength recordings to be performed using the WBB. This software has shown high reproducibility and concurrent validity for measuring isometric muscle strength in the lower limbs [21]. Next, we want to establish whether this software can be used for isometric HGS testing. Hence, the aim of this study was (1) to explore both relative and absolute reproducibility of the WBB to measure HGS in the dominate and the non-dominate hand and (2) to explore concurrent validity when compared to the gold standard, the JD.

\section{Method}

\section{Design}

Following the guidelines for reporting reliability and agreement studies (GRRAS) [22], we tested the intrarater reproducibility of the WBB performing tests one week apart. Concurrent validity was also explored by comparing the WBB to JD on the first session. Participants were randomized to start with either the WBB or JD in order to avoid order effects.

\section{Study-population}

Thirty older adults were recruited using the member lists from senior citizen clubs and organizations in Aalborg, Denmark. Using telephone interview, participants were included if they were 65 years or more, willing and able to come to the hospital twice within a week by themselves, and able to pass a small custom dementia screening (correctly answering the current year, month and prime minister of Denmark). Participants were excluded if they had acute illness within the previous 3 weeks, orthopaedic surgery on upper or lower limbs within 6 months or neurologic disease (e.g. Parkinson's disease, severe dementia). All participants gave written consent and the study was approved by the regional ethics committee, The North Denmark Region Committee on Health Research Ethics, which is appointed by The Regional Council of the North Denmark Region.

\section{Overall experimental and calibration procedures}

Participant characteristics such as height, weight, handedness, number of drugs taken and physical activity in hours per week were obtained prior to testing. All tests were performed at the same time-of-day, in the same clinical examination room at Aalborg University Hospital and by the same rater. The rater was a trained physiologist (MGJ). Devices were calibrated by applying known weights of $0.2,0.5,1.0,1.5,2,4,5,8,10,20,30$ and $50 \mathrm{~kg}$ to the force transducers.

\section{WBB}

WBB is a rigid square-shaped platform with four uniaxial vertial stain gauge transducers in the corners. Using Bluetooth HID wireless and custom programs written in C\#, data was streamed to a computer (Lenovo Yoga Pro, Windows 8). The software recorded the isometric force-time curve from the sensor values reported as four channels of 16-bit digital data samples at approximately $100 \mathrm{~Hz}$ and subsequently filtered using a 4th order Butterworth filter (cut-off frequency $20 \mathrm{~Hz}$ ). The resulting accuracy of the software is 100 gram on the whole measurement range (from 0 to $300 \mathrm{~kg}$ ).

Before starting the actual tests, participants received a set of standard instructions and demonstration of the procedure. Afterwards they were seated in a standard chair (seating height $43 \mathrm{~cm}$ ), which was used for all tests. Participants were then asked to hold the WBB with their left and right hand around the middle of the WBB with the lower face of the board towards their torso. All tests were initiated with the right hand, which held and squeezed the upper right corner. This was followed by the left hand holding and squeezing the upper left corner, as illustrated in Fig. 1. Prior to the actual testing, 2-3 sub-maximal recordings were performed. This served both as habituation and warm-up. After the warm-up, the actual tests were performed with a total of three

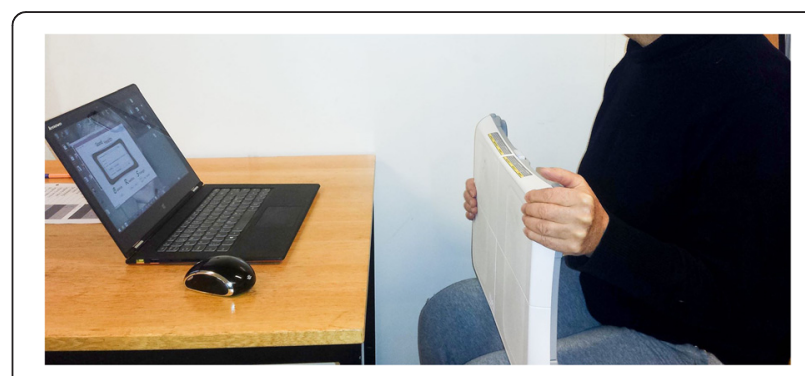

Fig. 1 Demonstration of a left hand grip strength measurement by pressing the upper left corner of the Nintendo Wii balance board 
measurements per hand alternating between right and left hand. The participants were encouraged to squeeze as long and as tightly as possible until a plateau had been reached. This took about 3-5 seconds and was visualized on the monitor which both the examiner and participant could see. The examiner instructed the participant when to stop. The participants rested their hands for 15 seconds before the next measurement.

\section{JD}

The JD (Lafayette Instruments Company, USA) is the most widely cited dynamometer in the literature and it is accepted as the gold standard by which other dynamometers are evaluated. It reads force in both kilograms and pounds, with markings at intervals of $2 \mathrm{~kg}$. According to our calibration procedures, the JD required a minimum of $2 \mathrm{~kg}$ to make the manometer move, which may be inappropriate when measuring very weak patients. Accordingly, it has been reported that the measurement error of the JD is greater at lower loadings [23].

Similar to the WBB test, participants received a set of standard instructions for the procedure followed by a demonstration. They performed 2-3 sub-maximal recordings prior to actual testing. In addition, participants rested their arm on a standard table (height $71 \mathrm{~cm}$ ) with the JD initially in the right hand followed by the left hand. The hand was positioned with the thumb on one side of the handle, while the other fingers were on the other side (see Fig. 2). The handle was set to position no 2. Similar to the WBB, a total of three measurements per hand were completed and the participants were encouraged to squeeze as long and tight as possible until a plateau had been reached.

\section{Statistics}

Data are presented as mean \pm standard deviation (SD), and all statistical analyses were performed using SPSS (version 22). The dominant and non-dominant hands were analysed separately and measurements were presented as first measurement, mean of two measurements, mean of three measurements and highest value out of three measurements. For reproducibility,

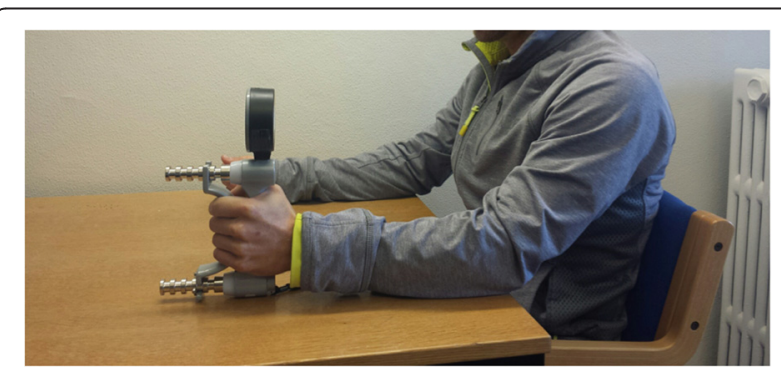

Fig. 2 Demonstration of a left hand grip strength measurement by pressing the Jamar handdynamometer the difference between session one and two (for WBB) was tested for normal distribution both statistically (Shapiro-Wilk) and visually (histogram). Further, the difference between each participant's individual score from the mean of the measurements in both sessions was plotted in a simple scatter plot for signs of heteroscedasticity [24]. Paired $t$ test was used to explore systematic bias between sessions. For relative reproducibility, intra-class correlation coefficient (ICC) was calculated with a $95 \%$ confidence intervals [25] using absolute agreement in a two-way mixed model, and the results of a single measurement was reported. The ICCs were interpreted based on the recommended ranges of poor $(<0.69)$, fair $(0.70-0.79)$, good (0.80-0.89), and high (0.90-1.00) for both relative reproducibility and validity [26]. For absolute reproducibility, the standard error of measurement (SEM) and limits of agreement (LOA) was calculated using the SD of the participants difference score between the two session multiplied by $\sqrt{1-I C C}$ and 1.96 , respectively [27]. The absolute values were also presented as percentages by dividing SEM and LOA with the mean value of all participants for both sessions.

For validity, Pearson's product-moment correlation between WBB and JD from session one were calculated for the first measurement, mean of two measurements, mean of three measurements and highest value of all three measurements. The correlations were interpreted as high ( $>0.70)$, moderate (0.50-0.69), low (0.26-0.49), and absent (0.00-0.25) [26]. To further support the validity analysis we included a calculation of ICC using a two-way mixed consistency model and reporting results of a single measurement.

\section{Results}

The study-population consisted of 18 women and 12 men with a mean age of $69 \pm 4.2$ years. Characteristics included height $168.5 \pm 6.9 \mathrm{~cm}$, weight $72.5 \pm 13.7 \mathrm{~kg}$, BMI $25.5 \pm 4.2 \mathrm{~kg} / \mathrm{m}^{2}$, number of medications $1.5 \pm 1.7$, while physical activity was $8.1 \pm 3.5$ hours per week. Two participants did not show up for session two. Their results were excluded for the reproducibility analysis, while their measurements from the first session were retained for the validity analysis.

In Fig. 3, the mean value for three measurements is shown for the WBB on both sessions and the JD. The between-subjects variation is greater than the withinsubject variation. Also, the JD reads on average higher values than the WBB. Post hoc analysis using the mean score of three measurements from the first session demonstrates an average difference of $15.4 \pm 5.5 \mathrm{~kg}$ for the dominant hand and $11.9 \pm 5.5 \mathrm{~kg}$ for the non-dominant hand with the JD giving higher values. 


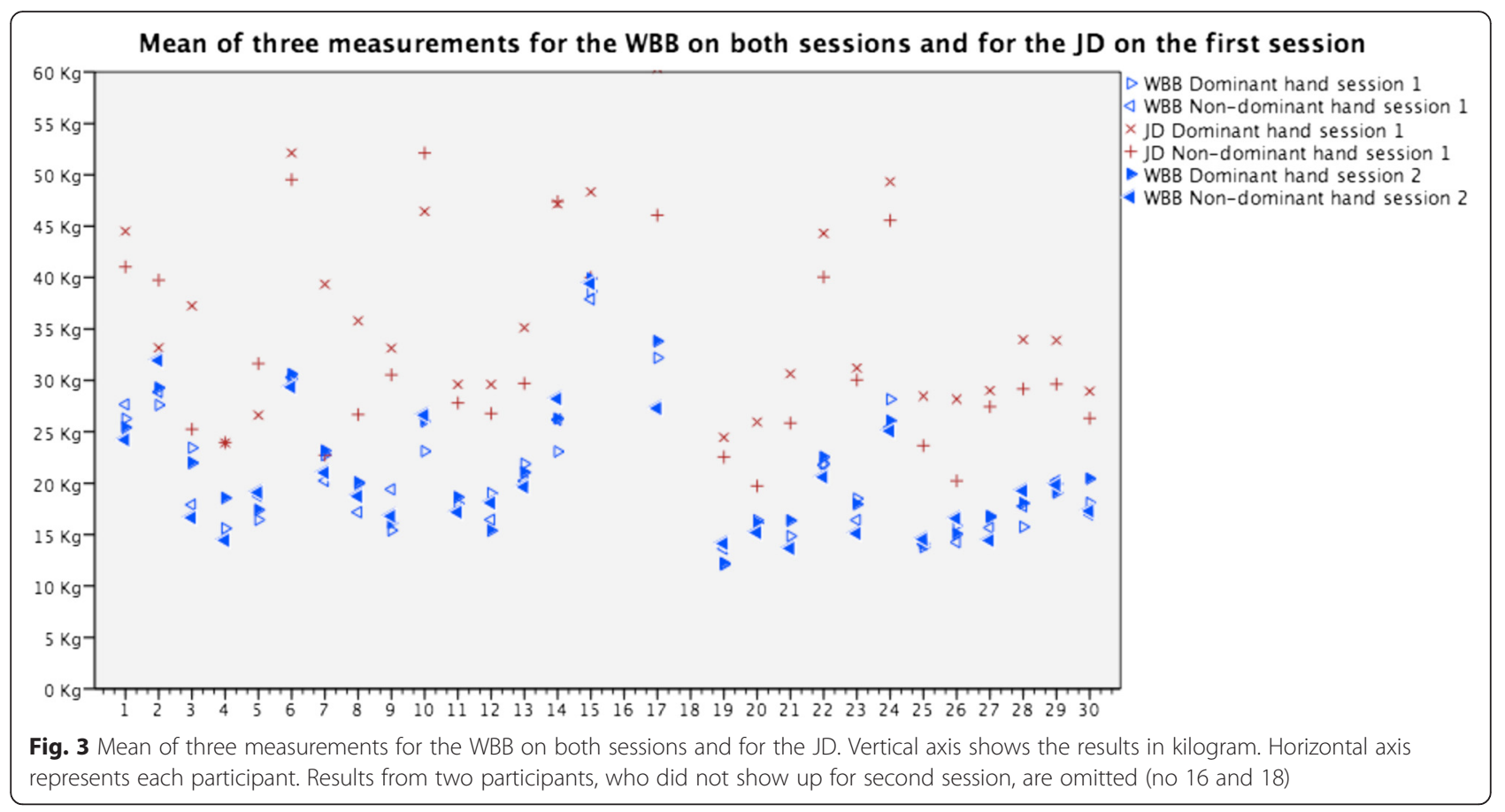

Reproducibility results for dominant and nondominant hands are shown in Tables 1 and 2, respectively. ICC values were $0.948-0.976$, SEM between 0.2 and $0.5 \mathrm{~kg}$ and LOA were between 2.7 and $4.2 \mathrm{~kg}$ across all measurements. There were no statistically significant differences between sessions one and two, and there were no visual signs of heteroscedasticity.

Validity results are shown in Tables 3 and 4. The Pearson correlations between WBB and JD for all measurements were between 0.80 and 0.88 with the differences being statistically significant, and ICC values were between 0.793 and 0.803 .

\section{Discussion}

To the best of our knowledge, this is the first report measuring HGS using the WBB. The results demonstrated good reproducibility for the WBB in measuring isometric HGS with ICC values similar to JD [23, 28-33], the gold standard for measuring HGS. In addition, SEM and LOA values were comparable to or lower than [34] those observed with the JD, reflecting an acceptable absolute reproducibility. Moreover, we found a high concurrent validity between the JD and WBB with Pearson's product-moment correlation averaging 0.85 . As expected, the Pearson correlation was somewhat lower than reported correlations between the JD and other handgrip dynamometers $[35,36]$. Still, the correlation was higher than that found between other HGS measurement techniques, such as the sphygmomanometer [37], grip-ball [32] and vigorimeter [38], and comparable to stationary alternatives, such as the BTW work simulator [39].

On the other hand, the ICC values between the JD and WBB were a bit weaker than the Pearson's correlations, ranging between fair and good (0.793-0.803). The confidence intervals for the ICC validity analysis were significantly wider than for the reproducibility analysis, spanning from 0.525 to 0.901 and thus encompassing

Table 1 Results from the reproducibility analysis for the dominant hand

\begin{tabular}{|c|c|c|c|c|c|c|c|c|}
\hline \multirow{2}{*}{$\begin{array}{l}\text { Dominant hand } \\
\text { Measurement(s) }\end{array}$} & \multicolumn{2}{|c|}{ Session 1} & \multicolumn{2}{|c|}{ Session 2} & \multirow[b]{2}{*}{ M-Diff (paired T-test) } & \multirow[b]{2}{*}{ ICC $[95 \% \mathrm{CI}]$} & \multirow[b]{2}{*}{ SEM (SEM\%) } & \multirow[b]{2}{*}{ LOA (LOA\%) } \\
\hline & MEAN & SD & MEAN & SD & & & & \\
\hline First measurement & 21.74 & 1.19 & 21.94 & 1.29 & 0.20 (n.s.) & $0.955[.906-.979]$ & $0.4(1.9)$ & $3.8(17.6)$ \\
\hline Mean of the two first measurements & 21.54 & 1.19 & 21.70 & 1.27 & 0.16 (n.s.) & $0.970[.937-.986]$ & $0.3(1.3)$ & $3.1(14.3)$ \\
\hline Mean of all three measurements & 21.37 & 1.18 & 21.60 & 1.23 & 0.23 (n.s.) & $0.966[.927-.985]$ & $0.3(1.4)$ & $3.1(14.6)$ \\
\hline Highest value of all three measurements & 22.33 & 1.19 & 22.81 & 1.34 & 0.48 (n.s.) & $0.960[.905-.982]$ & $0.4(1.6)$ & $3.4(15.4)$ \\
\hline
\end{tabular}

Mean, standard deviation (SD), standard error of measurement (SEM) and limits of agreement (LOA) in kilograms. M-diff is the mean difference in kilograms between the mean of the two sessions and the comparison using the paired T-test. n.s. not significant (all p-values are less than 0.001). SEM and LOA are also given in percentages (SEM\% and LOA\%). Intraclass correlation coefficient (ICC) with $95 \%$ confidence intervals [95\% CI] are given. Results are given for one measurement, mean of two measurements, mean of three measurements and highest value of three measurements 
Table 2 Results from the reproducibility analysis for the non-dominant hand

\begin{tabular}{|c|c|c|c|c|c|c|c|c|}
\hline \multirow{2}{*}{$\begin{array}{l}\text { Non-dominant hand } \\
\text { Measurement(s) }\end{array}$} & \multicolumn{2}{|c|}{ Session 1} & \multicolumn{2}{|c|}{ Session 2} & \multirow[b]{2}{*}{ M-Diff (paired T-test) } & \multirow[b]{2}{*}{$\mathrm{ICC}[95 \% \mathrm{Cl}]$} & \multirow[b]{2}{*}{ SEM (SEM\%) } & \multirow[b]{2}{*}{ LOA (LOA\%, } \\
\hline & MEAN & SD & MEAN & SD & & & & \\
\hline First measurement & 21.47 & 1.28 & 20.78 & 1.27 & -0.69 (n.s.) & $0.948[.891-.975]$ & $0.5(2.4)$ & $4.2(20.1)$ \\
\hline Mean of the two first measurements & 21.08 & 1.22 & 20.68 & 1.25 & -0.40 (n.s.) & $0.973[.943-.988]$ & $0.2(1.2)$ & $2.9(14.3)$ \\
\hline Mean of all three measurements & 21.30 & 1.20 & 20.65 & 1.23 & -0.65 (n.s.) & $0.976[.947-.989]$ & $0.2(1.1)$ & $2.7(13.3)$ \\
\hline Highest value of all three measurements & 22.30 & 1.24 & 21.61 & 1.32 & -0.69 (n.s.) & $0.961[.917-.982]$ & $0.4(1.7)$ & $3.7(16.8)$ \\
\hline
\end{tabular}

Mean, standard deviation (SD), standard error of measurement (SEM) and limits of agreement (LOA) in kilograms. M-diff is the mean difference in kilograms between the mean of the two sessions and the comparison using the paired T-test. n.s. not significant (all p-values are less than 0.001). SEM and LOA are also given in percentages (SEM\% and LOA\%). Intraclass correlation coefficient (ICC) with $95 \%$ confidence intervals [95\% Cl] are given. Results are given for one measurement, mean of two measurements, mean of three measurements and highest value of three measurements

the full range from poor to high correlations. Hence, we have less confidence on the ICCs for the validity analysis, which must be interpreted with caution. The result from our study also indicate lower errors of measurement when considering the mean value of two or three measurements rather than one measurement or the maximum of three measurements, which is consistent with other studies [40].

Although the WBB showed a acceptable correlation with the JD, there was a systematic difference in the results. On average this was $15.4 \pm 5.5 \mathrm{~kg}$ for the dominant hand and $11.9 \pm 5.5 \mathrm{~kg}$ for the non-dominant hand with the JD giving higher values. Hence, there is an interinstrument difference between the WBB and the JD, and the instruments are not interchangeable. However, this lack of agreement has also been found between different dynamometers [35, 41, 42] and even between different models of JD [43]. These studies [35, 41, 42] are consistent with our results in that the JD tends to give higher values when compared to other instruments.

Comparing our results from the dominant and nondominant hand there is similar reproducibility between hands, but a somewhat better correlation with the JD for the dominant side, both with Pearson's correlation (0.87 vs 0.82 on average) and ICC (.793 vs .768). The cause

Table 3 Results from the concurrent validity analysis for the dominant hand

\begin{tabular}{lll}
\hline Dominant hand & & \\
\hline Measurement(s) & $\begin{array}{l}\text { Pearson's product-moment } \\
\text { correlation }\end{array}$ & $\begin{array}{l}\text { ICC } \\
{[95 \% \mathrm{Cl}]}\end{array}$ \\
\hline First measurement & $0.88(p<0.001)$ & .793 \\
& $0.88(p<0.001)$ & .803 \\
$\begin{array}{l}\text { Mean of the two first } \\
\text { measurements }\end{array}$ & {$[.626-.901]$} \\
$\begin{array}{l}\text { Mean of all three } \\
\text { measurements }\end{array}$ & .786 \\
$\begin{array}{l}\text { Highest value of all three } \\
\text { measurements }\end{array}$ & $0.87(p<0.001)$ & {$[.597-.892]$} \\
$\begin{array}{l}\text { Intraclass correlation coefficient }(\mathrm{ICC}) \text { with } 95 \% \text { confidence intervals }[95 \% \mathrm{CI}] \\
\text { and Pearson's product-moment correlation with } p \text {-values are given for one }\end{array}$ \\
$\begin{array}{l}\text { measurement, mean of two measurements, mean of three measurements and } \\
\text { highest value of three measurements. All measurements are from session 1 }\end{array}$
\end{tabular}

for this difference cannot be deduced from our results, but it might be expected that the strength difference between the two sides will result in lower correlation for the weaker side, i.e. non-dominant side (about $5 \%$ weaker according to our results), since the JD allows assessment to the nearest kilogram, while the WBB allows assessment down to the nearest 100 gram. In combination with the increased measurement error for lower loadings with the JD, this may explain the difference observed.

One limitation with the WBB method for measuring HGS is the lack of adjustable handles to accommodate different hand sizes. Thus, the effect of hand size on our method is unknown. Still, this is the first investigation of HGS using the WBB. Compared to the above mentioned techniques the WBB has advantages in that it is a lowcost, portable and wide-spread tool. Furthermore, it has the potential for multiple roles in the clinical setting. This may include objectified measurements of reactiontime [19], balance [18] and lower limb muscle strength [21]. The data presented here demonstrate the applicability of an additional facility, the HGS. The WBB has also been successfully used as an intervention tool for balance in healthy eldery [44], as well as in chronic diseases $[45,46]$ and for physical rehabilitation [47-49].

Table 4 Results from the concurrent validity analysis for the non-dominant hand

\begin{tabular}{lll}
\hline Non-dominant hand & & \\
\hline Measurement(s) & $\begin{array}{l}\text { Pearson's product-moment } \\
\text { correlation }\end{array}$ & $\begin{array}{l}\text { ICC } \\
{[95 \% \mathrm{Cl}]}\end{array}$ \\
\hline First measurement & $0.80(p<0.001)$ & .763 \\
& & {$[.559-.880]$} \\
Mean of the two first & $0.80(p<0.001)$ & .748 \\
measurements & & {$[.535-.872]$} \\
Mean of all three & $0.82(p<0.001)$ & .768 \\
measurements & & {$[.562-.882]$} \\
Highest value of all three & $0.86(p<0.001)$ & .794 \\
measurements & & {$[.611-.896]$} \\
\hline
\end{tabular}

Intraclass correlation coefficient (ICC) with $95 \%$ confidence intervals $[95 \% \mathrm{Cl}]$ and Pearson's product-moment correlation with $p$-values are given for one measurement, mean of two measurements, mean of three measurements and highest value of three measurements. All measurements are from session 1 
Finally, the multiple use of one instrument with rapid and automatic transferral of measurements to the computer system prevents loss of results and error in reporting, and it supports optimal use of staff time.

This study has both strengths and weaknesses. Firstly, we did not investigate inter-rater reliability. The impact on WBB results is likely to be limited as the results are read automatically and hand positioning is likely to be similar between raters. Secondly, the participants positioning deviates from the standardised procedure recommended by American Society of Hand Therapists [16], but only by having a slightly more extended elbow position. The magnitude of this limitation is likely to be minimal. Thirdly, we only investigated independent older adults with a high level of functioning, as evaluated by their physical activity. Caution should be taken for generalizing the results to other age groups and populations. Still, this study had a sufficient number of participants for the purpose under study, and the methods have been reported in sufficient detail with the relevant statistics according to the GRRAS.

\section{Conclusion}

Reproducibility for WBB was high for relative measures and acceptable for absolute measures in both dominant and non-dominant hands in a cohort of older adults. In addition, an acceptable concurrent validity was found between the JD and the WBB. Thus, the WBB appears to be a valid and reliable instrument when assessing HGS in older adults and may be a useful tool in clinical settings. Further research should aim to establish the inter-rater reproducibility and to explore the method in other populations.

\section{Availability of Data and Materials}

Raw material can be provided upon request, please contact AWB or MGJ.

\section{Abbreviations}

HGS: Hand grip strength; WBB: Nintendo Wii Balance Board; JD: Jamar handdynamometer; SEM: Standard error of measurement; LOA: Limits of agreement; ICC: Intraclass correlation coefficient; GRRAS: Guidelines for reporting reliability and agreement studies.

\section{Competing interests}

AWB, SA and EDB declare that they have no competing interests. MGJ developed and holds a patent on the software used in the study.

\section{Author contributions}

AWB, principal investigator of this study, analysed the data and drafted the first version of the manuscript. MGJ designed the study and collected the data. AWB, SA, EDB and MGJ substantially contributed to the design and the interpretation of data for the work, revising the first manuscript critically for important intellectual content, gave final approval of the version to be published and agree being accountable for all aspects of the work related to the accuracy and integrity of the work.

\section{Author details}

'Department of Geriatric and Internal Medicine, Aalborg University Hospital, Aalborg, Denmark. ${ }^{2}$ Department of Clinical Medicine, Aalborg University, Aalborg, Denmark. ${ }^{3}$ Department of Health Sciences and Technology, Institute of Human Movement Sciences and Sport, ETH Zurich, Zurich, Switzerland.

Received: 3 November 2015 Accepted: 27 January 2016

Published online: 03 February 2016

\section{References}

1. Morey MC, Pieper CF, Cornoni-Huntley J. Physical fitness and functional limitations in community-dwelling older adults. Med Sci Sports Exerc. 1998; 30(5):715-23. http://www.ncbi.nlm.nih.gov/pubmed/9588614. Accessed 24 Jun 2015

2. Newman AB, Kupelian V, Visser M, Simonsick EM, Goodpaster BH, Kritchevsky SB, et al. Strength, but not muscle mass, is associated with mortality in the health, aging and body composition study cohort. J Gerontol A Biol Sci Med Sci. 2006;61(1):72-7. http://www.ncbi.nlm.nih.gov/ pubmed/16456196. Accessed 18 Jun 2015.

3. Metter EJ, Talbot LA, Schrager M, Conwit R. Skeletal muscle strength as a predictor of all-cause mortality in healthy men. J Gerontol A Biol Sci Med Sci. 2002;57(10):B359-65. http://www.ncbi.nlm.nih.gov/pubmed/12242311. Accessed 4 Jun 2015.

4. Rantanen T, Guralnik JM, Foley D, Masaki K, Leveille S, Curb JD, et al. Midlife hand grip strength as a predictor of old age disability. JAMA. 1999;281(6): 558-60. http://www.ncbi.nlm.nih.gov/pubmed/10022113. 25 Accessed Jun 2015

5. Fujita Y, Nakamura Y, Hiraoka J, Kobayashi K, Sakata K, Nagai M, et al. Physical-strength tests and mortality among visitors to health-promotion centers in Japan. J Clin Epidemiol. 1995;48(11):1349-59. http://www.ncbi. nlm.nih.gov/pubmed/7490598. Accessed 18 Jun 2015.

6. Rantanen T, Volpato S, Ferrucci L, Heikkinen E, Fried LP, Guralnik JM. Handgrip strength and cause-specific and total mortality in older disabled women: exploring the mechanism. J Am Geriatr Soc. 2003;51(5):636-41. http://www.ncbi.nlm.nih.gov/pubmed/12752838. Accessed 18 Jun 2015.

7. Rantanen T, Harris T, Leveille SG, Visser M, Foley D, Masaki K, et al. Muscle strength and body mass index as long-term predictors of mortality in initially healthy men. J Gerontol A Biol Sci Med Sci. 2000;55(3):M168-73. http://www.ncbi.nlm.nih.gov/pubmed/10795731. Accessed 18 Jun 2015.

8. Sasaki H, Kasagi F, Yamada M, Fujita S. Grip strength predicts cause-specific mortality in middle-aged and elderly persons. Am J Med. 2007;120(4):337-42. doi:10.1016/j.amjmed.2006.04.018.

9. Norman K, Stobäus N, Gonzalez MC, Schulzke J-D, Pirlich M. Hand grip strength: outcome predictor and marker of nutritional status. Clin Nutr. 2011;30(2):135-42. doi:10.1016/j.cInu.2010.09.010.

10. Flood A, Chung A, Parker H, Kearns V, O'Sullivan TA. The use of hand grip strength as a predictor of nutrition status in hospital patients. Clin Nutr. 2014:33(1):106-14. doi:10.1016/j.clnu.2013.03.003.

11. Phillips P. Grip strength, mental performance and nutritional status as indicators of mortality risk among female geriatric patients. Age Ageing. 1986;15(1):53-6. http://www.ncbi.nlm.nih.gov/pubmed/3953331. Accessed 18 Jun 2015.

12. Bohannon RW. Manual muscle testing: does it meet the standards of an adequate screening test? Clin Rehabil. 2005;19(6):662-7. http://www.ncbi. nlm.nih.gov/pubmed/16180603. Accessed 25 Jun 2015.

13. Hayes K, Walton JR, Szomor ZL, Murrell GAC. Reliability of 3 methods for assessing shoulder strength. J Shoulder Elbow Surg. 11(1):33-39. doi:10. 1067/mse.2002.119852.

14. Innes E. Handgrip strength testing: A review of the literature. Aust Occup Ther J. 1999;46(3):120-40. doi:10.1046/j.1440-1630.1999.00182.x.

15. Abizanda P, Navarro JL, García-Tomás MI, López-Jiménez E, Martínez-Sánchez E, Paterna G. Validity and usefulness of hand-held dynamometry for measuring muscle strength in community-dwelling older persons. Arch Gerontol Geriatr. 54(1):21-27. doi:10.1016/j.archger.2011.02.006.

16. Roberts HC, Denison HJ, Martin HJ, Patel HP, Syddall H, Cooper C, et al. A review of the measurement of grip strength in clinical and epidemiological studies: towards a standardised approach. Age Ageing. 2011;40(4):423-9. doi:10.1093/ageing/afr051.

17. Bohannon RW. Hand-grip dynamometry predicts future outcomes in aging adults. J Geriatr Phys Ther. 2008:31(1):3-10. http://www.ncbi.nlm.nih.gov/ pubmed/18489802. Accessed 11 Jun 2015. 
18. Clark RA, Bryant AL, Pua Y, McCrory P, Bennell K, Hunt M. Validity and reliability of the Nintendo Wii Balance Board for assessment of standing balance. Gait Posture. 2010;31(3):307-10. doi:10.1016/j.gaitpost.2009.11.012.

19. Jorgensen MG, Paramanathan S, Ryg J, Masud T, Andersen S. Novel use of the Nintendo Wii board as a measure of reaction time: a study of reproducibility in older and younger adults. BMC Geriatr. 2015;15:80. doi:10.1186/s12877-015-0080-6.

20. Bartlett $H L$, Ting $L H$, Bingham JT. Accuracy of force and center of pressure measures of the Wii Balance Board. Gait Posture. 2014;39(1):224-8. doi:10.1016/j.gaitpost.2013.07.010.

21. Gronbech Jorgensen M, Andersen S, Ryg J, Masud T. Novel Use of the Nintendo Wii Board for Measuring Isometric Lower Limb Strength: A Reproducible and Valid Method in Older Adults. PLoS One. 2015;10(10): e0138660. doi:10.1371/journal.pone.0138660

22. Kottner J, Audige L, Brorson S, Donner A, Gajewski BJ, Hróbjartsson A, et al. Guidelines for Reporting Reliability and Agreement Studies (GRRAS) were proposed. Int J Nurs Stud. 2011; 48(6):661-71. doi:10.1016/j.jpurstu.2011.01.016

23. Hogrel J-Y. Grip strength measured by high precision dynamometry in healthy subjects from 5 to 80 years. BMC Musculoskelet Disord. 2015;16(1): 139. doi:10.1186/s12891-015-0612-4

24. Bland JM, Altman DG. Statistical methods for assessing agreement between two methods of clinical measurement. Lancet. 1986;1(8476):307-10. http://www.ncbi.nlm.nih.gov/pubmed/2868172. Accessed 9 Jul 2014

25. Hopkins WG. Measures of reliability in sports medicine and science. Sports Med. 2000;30(1):1-15. http://www.ncbi.nlm.nih.gov/pubmed/10907753. Accessed 1 Sept 2015.

26. Domholdt E. Physical Therapy Research Principles and Application. Philadelphia: WB Saunders; 1993.

27. Atkinson G, Nevill AM. Statistical methods for assessing measurement error (reliability) in variables relevant to sports medicine. Sports Med. 1998;26(4): 217-38. http://www.ncbi.nlm.nih.gov/pubmed/9820922. Accessed 11 Sept 2015.

28. Bohannon RW, Schaubert KL. Test-retest reliability of grip-strength measures obtained over a 12-week interval from community-dwelling elders. J Hand Ther. 2005:18(4):426-7. doi:10.1197/j.jht.2005.07.003. quiz 428.

29. Gerodimos V. Reliability of handgrip strength test in basketball players. J Hum Kinet. 2012;31:25-36. doi:10.2478/v10078-012-0003-y.

30. Savva C, Giakas G, Efstathiou M, Karagiannis C. Test-retest reliability of handgrip strength measurement using a hydraulic hand dynamometer in patients with cervical radiculopathy. J Manipulative Physiol Ther. 2014;37(3): 206-10. doi:10.1016/j.jmpt.2014.02.001.

31. Peolsson A, Hedlund R, Oberg B. Intra- and inter-tester reliability and reference values for hand strength. J Rehabil Med. 2001;33(1):36-41. http:// www.ncbi.nlm.nih.gov/pubmed/11480468. Accessed 3 Sept 2015.

32. Vermeulen J, Neyens JCL, Spreeuwenberg MD, van Rossum E, Hewson DJ, de Witte LP. Measuring grip strength in older adults: comparing the gripball with the Jamar dynamometer. J Geriatr Phys Ther. 38(3):148-153. doi:10. 1519/JPT.0000000000000034

33. Fox B, Henwood T, Neville C, Keogh J. Relative and absolute reliability of functional performance measures for adults with dementia living in residential aged care. Int Psychogeriatr. 2014;26(10):1659-67. doi:10.1017/S1041610214001124.

34. Coldham F, Lewis J, Lee $H$. The reliability of one vs. three grip trials in symptomatic and asymptomatic subjects. J Hand Ther. 2006;19(3):318-26. doi:10.1197/j.jht.2006.04.002. quiz 327.

35. Shechtman O, Gestewitz L, Kimble C. Reliability and validity of the DynEx dynamometer. J Hand Ther. 2005;18(3):339-47. doi:10.1197/j.jht.2005.04.002.

36. Mathiowetz V. Comparison of Rolyan and Jamar dynamometers for measuring grip strength. Occup Ther Int. 2002;9(3):201-9. http://www.ncbi. nlm.nih.gov/pubmed/12374997. Accessed 3 Sept 2015.

37. Hamilton GF, McDonald C, Chenier TC. Measurement of grip strength: validity and reliability of the sphygmomanometer and jamar grip dynamometer. J Orthop Sports Phys Ther. 1992;16(5):215-9. doi:10.2519/jospt.1992.16.5.215.

38. Fike ML, Rousseau E. Measurement of Adult Hand Strength: A Comparison of Two Instruments. OTJR Occup Particip Heal. 1982;2(1):43-9. doi:10.1177/153944928200200105.

39. Beaton DE, O'Driscoll SW, Richards RR. Grip strength testing using the BTE work simulator and the jamar dynamometer: A comparative study. J Hand Surg Am. 1995;20(2):293-8. doi:10.1016/S0363-5023(05)80029-2.
40. Mathiowetz V, Weber K, Volland G, Kashman N. Reliability and validity of grip and pinch strength evaluations. J Hand Surg Am. 1984;9(2):222-6. http://www.ncbi.nlm.nih.gov/pubmed/6715829. Accessed 3 Sept 2015

41. Massy-Westropp N, Rankin W, Ahern M, Krishnan J, Hearn TC. Measuring grip strength in normal adults: reference ranges and a comparison of electronic and hydraulic instruments. J Hand Surg Am. 2004;29(3):514-9. doi:10.1016/j.jhsa.2004.01.012.

42. Amaral JF, Mancini M, Novo Júnior JM. Comparison of three hand dynamometers in relation to the accuracy and precision of the measurements. Rev Bras Fisioter. 2012;16(3):216-24. http://www.ncbi.n/m. nih.gov/pubmed/22801514. Accessed 19 Sept 2015.

43. Flood-Joy M, Mathiowetz V. Grip-Strength Measurement: A Comparison of Three Jamar Dynamometers. OTJR Occup Particip Heal. 1987;7(4):235-43. doi:10.1177/153944928700700405.

44. Bieryla KA, Dold NM. Feasibility of Wii Fit training to improve clinical measures of balance in older adults. Clin Interv Aging. 2013;8:775-81. doi:10.2147/CIA.S46164.

45. Prosperini L, Fortuna D, Giannì C, Leonardi L, Marchetti MR, Pozzilli C. Home-based balance training using the Wii balance board: a randomized, crossover pilot study in multiple sclerosis. Neurorehabil Neural Repair. 27(6): 516-525. doi:10.1177/1545968313478484.

46. Gonçalves GB, Leite MAA, Orsini M, Pereira JS. Effects of using the nintendo wii fit plus platform in the sensorimotor training of gait disorders in Parkinson's disease. Neurol Int. 2014;6(1):5048. doi:10.4081/ni.2014.5048.

47. Negus JJ, Cawthorne DP, Chen JS, Scholes CJ, Parker DA, March LM. Patient outcomes using Wii-enhanced rehabilitation after total knee replacement the TKR-POWER study. Contemp Clin Trials. 2015;40:47-53. doi:10.1016/j.cct.2014.11.007.

48. Baltaci G, Harput G, Haksever B, Ulusoy B, Ozer H. Comparison between Nintendo Wii Fit and conventional rehabilitation on functional performance outcomes after hamstring anterior cruciate ligament reconstruction: prospective, randomized, controlled, double-blind clinical trial. Knee Surgery, Sport Traumatol Arthrosc. 2012;21(4):880-7. doi:10.1007/s00167-012-2034-2.

49. Bower KJ, Clark RA, McGinley JL, Martin CL, Miller KJ. Clinical feasibility of the Nintendo $\mathrm{Wi}^{\mathrm{TM}}$ for balance training post-stroke: a phase II randomized controlled trial in an inpatient setting. Clin Rehabil. 2014;28(9):912-23. doi: 10.1177/0269215514527597.

\section{Submit your next manuscript to BioMed Central and we will help you at every step:}

- We accept pre-submission inquiries

- Our selector tool helps you to find the most relevant journal

- We provide round the clock customer support

- Convenient online submission

- Thorough peer review

- Inclusion in PubMed and all major indexing services

- Maximum visibility for your research

Submit your manuscript at www.biomedcentral.com/submit
) Biomed Central 